\title{
Correction to: The Association Between Clinician and Perceived Organizational Factors with Early Fidelity to Cognitive Processing Therapy for Posttraumatic Stress Disorder in a Randomized Controlled Implementation Trial
}

\author{
Iris Sijercic ${ }^{1} \cdot$ Jeanine E. M. Lane ${ }^{1} \cdot$ Cassidy A. Gutner ${ }^{2} \cdot$ Candice M. Monson $^{1} \cdot$ Shannon Wiltsey Stirman $^{3}$ \\ Published online: 10 September 2019 \\ (c) Springer Science+Business Media, LLC, part of Springer Nature 2019
}

\section{Correction to: \\ Administration and Policy in Mental Health and Mental Health Services Research \\ https://doi.org/10.1007/s10488-019-00966-7}

The article "The Association Between Clinician and Perceived Organizational Factors with Early Fidelity to Cognitive Processing Therapy for Posttraumatic Stress Disorder in a Randomized Controlled Implementation Trial", written by Iris Sijercic, Jeanine E. M. Lane, Cassidy A. Gutner, Candice M. Monson and Shannon Wiltsey Stirman, was originally published electronically on the publisher's internet portal (currently SpringerLink) on 28 August 2019 with open access. With the author(s)' decision to step back from Open Choice, the copyright of the article changed on 30 August 2019 to $\odot$ Springer Science+Business Media, LLC, part of Springer Nature 2019 and the article is forthwith distributed under the terms of copyright.

The original article has been corrected.

Publisher's Note Springer Nature remains neutral with regard to jurisdictional claims in published maps and institutional affiliations.
The original article can be found online at https://doi.org/10.1007/ s10488-019-00966-7.

Shannon Wiltsey Stirman

sws1@stanford.edu

Ryerson University, Toronto, Canada

Boston University School of Medicine, Boston, USA

3 National Center for PTSD, VA Palo Alto Healthcare System \& Stanford University, 795 Willow Road, NC-PTSD 334, Menlo Park, CA 94025, USA 